\title{
Landing Styles Influences Reactive Strength Index without Increasing Risk for Injury
}

\section{(ㄷ) (1) $(\mathrm{)})$}

\author{
Authors \\ Dana Guy-Cherry ${ }^{1}$, Ahmad Alanazi², Lauren Miller ${ }^{1}$, Darrin Staloch ${ }^{1}$, Alexis Ortiz-Rodriguez ${ }^{3}$
}

\author{
Affiliations \\ 1 Texas Woman's University, School of Physical Therapy, \\ Houston, United States \\ 2 Majmaah University, Physical Therapy, Al Majma'ah, \\ Saudi Arabia \\ 3 UT Health San Antonio, Department of Physical Therapy, \\ San Antonio, United States
}

Key words landing, knee, valgus, jumping, drop jump

received 13.12 .2017

revised 28.03.2018

accepted 05.04.2018

\section{Bibliography}

DOI https://doi.org/10.1055/a-0608-4280

Sports Medicine International Open 2018; 2: E35-E40

(c) Georg Thieme Verlag KG Stuttgart - New York

ISSN 2367-1890

\section{Correspondence}

Dr. Alexis Ortiz-Rodriguez

UT Health San Antonio

Department of Physical Therapy

7703 Floyd Curl Drive

78229 San Antonio

United States

Tel.: + 1/210/567 8750, Fax: + 1/210/567 8774

ortiza7@uthscsa.edu

\begin{abstract}
The aim was to determine which three landing styles - stiff(ST), self-selected (SS), or soft (SF) - exhibit safer landing mechanics and greater jumping performance. Thirty participants (age: $26.5 \pm 5.1$ years; height: $171.0 \pm 8.8 \mathrm{~cm}$; weight: $69.7 \pm 10.1 \mathrm{~kg}$ ) performed five trials of three randomized drop jump $(40 \mathrm{~cm})$ landing styles including SF ( $60^{\circ}$ knee flexion), ST (knees as straight as possible), and SS. Knee flexion and valgus angles and kinetics were measured. An electromyography system measured muscle activity of the gluteus maximus, quadriceps, hamstrings, tibialis anterior, and gastrocnemius. Reactive strength index (RSI) was used to measure jumping performance. ANOVAs were used to compare the three landings. All landings differed in knee flexion ( $p<0.001$; effect size $\left(\eta^{2}\right)$ : 0.9$)$ but not valgus $(p=.13$; $\left.\eta^{2}: .15\right)$. RSI $\left(\mathrm{mm} \cdot \mathrm{ms}^{-1}\right)$ showed differences for all jumps $\left(p<0.001 ; \eta^{2}: 0.7\right)$ with SS (0.96) showing the highest value, then ST (0.93), and SF (0.64). Ground reaction forces were different between jumps $\left(p<0.001 ; \eta^{2}: 0.4\right)$ with SF (1.34/bodyweight (bw)) showing lower forces, then SS (1.50/bw), and ST (1.81/ bw). No between-jump differences were observed for EMG ( $p>0.66 ; \eta^{2}: 0.3$ ). No landing demonstrated valgus landing mechanics. The SS landing exhibited the highest RSI. However, the 1.8/bw exhibited by the ST landing might contribute to overload of musculotendinous structures at the knee.
\end{abstract}

\section{Introduction}

Injuries to the anterior cruciate ligament $(\mathrm{ACL})$ have been rising dramatically in both male and female athletes in the last few decades; with up to $84 \%$ occurring during noncontact activities $[3,16,20]$. One of the most common scenarios for a noncontact ACL tear is landing from a jump $[3,19,25]$. Therefore, considerable research and clinical attention has been devoted to identifying the potential factors contributing to the increased loads imposed on the ACL during landing. Knee flexion and knee valgus joint angles have a significant impact on the load imposed on the ACL during landing
$[15,18,22,31]$. Several researchers have reported that small knee flexion and large knee valgus joint angles during landing increase the load on the $A C L$, resulting in greater risk of $A C L$ injuries [15, 18, 22, 31].

Landing styles play a major role in reducing the risk of ACL injury [7]. Soft landing styles are thought to positively alter landing mechanics by allowing the knee joint to be in a slightly flexed position, increasing impact absorption at ground contact [7] and subsequently decreasing ACL loading $[8,23,28,43,49]$. Dai et al. [7] found that verbally encouraging athletes to land softly significantly increased maximum knee flexion angles compared with self-selected and stiff landings [7]. Therefore, some 
researchers claim that the soft landing technique is one of the strategies that should be emphasized to decrease the load on the ACL during landing maneuvers [7,27]. Conversely, previous laboratory studies have reported that a landing style characterized by a more extended knee position may generate greater ground reaction forces during landing $[10,50]$, increasing anterior tibial displacement to which the $A C L$ is the predominant restraint $[41,49]$.

Landing style has a significant influence on jumping performance $[7,12,33,47]$. In many sport disciplines, athletes are required to frequently perform a series of repetitive maximal jumps throughout a game $[29,30]$. However, landing with increased knee flexion, which is currently utilized to decrease ACL injury risk, is associated with decreased jump height [7,32]. Therefore, athletes tend to modify their landing technique by decreasing knee flexion, exhibiting a stiff landing style, in order to maximize their jumping performance [7, 29, 30, 32]. Despite smaller knee flexion joint angles typically improving jumping performance, it has been reported to increase the loads on the ACL during landing [7]. However, it has been argued that with the appropriate eccentric muscular control from the quadriceps muscle group, stiff landings can be performed in a safe manner without jeopardizing performance [7]. However, no previous studies have addressed EMG of lower extremity muscles.

Injury prevention programs have been reported to be effective in reducing knee injuries including ACL tears by correcting faulty biomechanics $[11,14,44]$. Although their documented effectiveness in reducing injuries has been recognized, coaches lack the motivation to perform such programs. The main reasons are related to the emphasis on injury prevention without any evidence for improvement in performance and also the time needed to perform these programs interfering with the training schedule and skill development $[42,44]$. Two studies have found deleterious effects on jumping height, agility, strength, and sprinting speed in soccer athletes participating in injury prevention programs hypothesized to be caused by performing landings in a deep controlled (slow) manner [42,44]. Therefore, the purpose of this study was to determine which of the three landing techniques (soft, self-selected, and stiff) demonstrated safer landing mechanics, greater jumping performance, and enhanced muscle activation. We hypothesized that both stiff and self-selected landing techniques would demonstrate greater jumping performance due to reduced ground contact time with the floor and that these tasks can be performed in a safe manner without increasing the risk for knee valgus while maintaining good muscular control.

\section{Methods}

\section{Study design}

A cross-sectional laboratory study was conducted to evaluate landing mechanics during three landing techniques: soft (SF), self-selected (SS) and stiff (ST). The dependent variables included knee flexion and knee valgus angles, neuromuscular performance by electromyography root mean square (EMG), and reactive strength index (RSI).

\section{Participants}

Thirty participants (men: 16; women: 14; age: $26.5 \pm 5.1$ years; height: $171.0 \pm 8.8 \mathrm{~cm}$; weight: $69.7 \pm 10.1 \mathrm{~kg}$; BMl: $23.75 \pm 2.52 \mathrm{~kg} /$ $\mathrm{cm}^{2}$ ) were recruited in this study using convenience sampling from the undergraduate and graduate collegiate community. This sample size was based on a priori power analyses using a repeated measures analysis of variance (RepANOVA) for three conditions (jumps) and main variables of interest (joint angles, ground reactions forces, and jumping performance) with an effect size of 0.2 , alpha level of 0.05 , and a power of $80 \%$. All participants read and signed an informed consent form approved by the Institutional Review Board meeting the ethical standards of the journal [21]. Inclusion criteria were: 1 ) age between 18 and 35 years, and 2) being physically active (minimum of 3 hours/week of recreational fitness activities). Exclusion criteria included low back or lower extremity surgery or injury, inability to perform 2 single-legged screening jumps, leg length discrepancy of more than $2 \mathrm{~cm}$ determined by a measuring tape from the anterior superior iliac spine to medial malleolus, $\mathrm{ACL}$ deficiency (more than $3 \mathrm{~mm}$ bilateral discrepancy) as measured by KT-1000 (MEDmetric Corp, San Diego, CA, USA) and self-reported pregnancy.

\section{Instrumentation}

A motion analysis system consisting of 10 cameras at a sampling rate of $240 \mathrm{~Hz}$ was used to capture lower extremity kinematics (Vicon Nexus 1.8, Vicon Motion Systems, Denver, CO, USA). Participants had fifteen retroreflective markers attached to the skin of the pelvis and both lower extremities according to Vicon's Plug-in Gait model $[24,45]$. Markers were placed at the second sacral vertebrae and bilaterally at the anterior superior iliac spines, lateral femoral epicondyles, mid-thigh (midpoint between greater trochanter and lateral femoral epicondyles), lateral malleoli, mid-shank (midpoint between lateral femoral epicondyles and lateral malleoli), calcaneal tuberosity and second metatarsophalangeal joint. Before data collection, the system was calibrated according to the manufacturer's recommendations and a static standing trial was performed.

A wireless surface electromyography (EMG) system (Trigno, Delsys, Inc., Boston, USA; bandwidth: $450 \pm 50 \mathrm{~Hz}>80 \mathrm{~dB} / \mathrm{dec}$; overall channel noise: $<0.75 \mathrm{uV}$ ) was utilized to measure muscle activity of the gluteus maximus, quadriceps, hamstrings, tibialis anterior, and gastrocnemius in both legs at a sampling rate of $2 \mathrm{kHz}$ with EMGWorks software (Delsys, Inc., Boston, MA, USA). Muscular activity was recorded using silver surface electrodes attached over the skin of muscles of interest based on Criswell [5] by using double-sided hypoallergenic tape. The skin was cleansed with alcohol before electrode placement. Hypoallergenic tape was applied over the electrodes to minimize movement artifact.

A wireless F-Scan insole pressure system $(100 \mathrm{~Hz}$; Tekscan Inc., Boston, MA, USA) was used to measure ground reaction forces (GRFs) via in-shoe pressure sensors. This system uses two thin insole sensors that were placed inside the shoes of each participant. The insole pressure system was calibrated according to the manufacturer's guidelines using the weight of each subject. This system has shown high correlations $(r=0.7-0.90)$ when compared to force plates [4] and good reliability (ICCs $\geq 0.9$ ) in diverse populations $[1,40,46]$. The specific trial-to-trial reliability of the pressure measurements in this investigation were $0.82,0.83$, and 0.74 for the SF, ST, and SS landings, respectively. Preliminary data from our laboratory have estimated a high significant correlation $(r=0.80$; $p<0.001$ ) between the F-Scan and force plates [2]. EMG and insole 
pressure instruments were timed-synchronized to the motion capture system.

\section{Procedures}

Age, height, and weight were obtained from each participant. Participants were then asked to perform two single-legged screening jumps to ensure safe jumping performance. Each participant performed a warm-up protocol consisting of five minutes on a cycle ergometer at $40-60$ revolutions per minute, 10 half $\left(90^{\circ}\right)$ squats and five countermovement jumps. Within 10-15 min following the warm-up protocol, reflective markers were attached to each participant according to Vicon Plug-in Gait model $[24,45]$ followed by placement of EMG electrodes over muscles of interest, and the two F-Scan insole sensors were placed inside each participant's shoes. The EMG electrode was secured to the skin with hypoallergenic double-sided tape between the skin and electrode and hypoallergenic paper tape over electrode to prevent any movement artifact. The inshoe pressure sensors were secured to the shoe's insole with double-sided tape to prevent any sliding of the sensor inside the shoe.

The three landing techniques were (1) SF, (2) SS, and (3) ST landing performed in a randomized order from a $40-\mathrm{cm}$ platform. Randomization and order of test selection was performed before the warm-up by shuffling three cards with the tests written on them and blindly selecting one card at a time. The instructions given to each participant were similar to those previously reported by Dai et al. [7]. During the SF landing, participants were instructed to jump off the platform and land in a squat of approximately 60 degrees of knee flexion and then jump off the floor as fast and high as possible [6]. In the SS landing, participants were instructed to jump off the platform and land at their SS squat depth and jump as high and fast as possible after landing. In the ST landing, participants were instructed to jump off a box and land with knees as straight as possible and then jump as fast and high as possible. No additional feedback was provided to participants during testing. Each participant performed five trials of each landing technique with 45-60 s rest between trials and three minutes between landing conditions because this number of trials is the minimum necessary for reliable kinematic results [36].

\section{Data reduction}

Knee flexion, valgus angles, and neuromuscular activation were measured during the landing phase of each functional task ( $\vee$ Fig. 1). In the present study, the landing phase of each landing style was defined as the period of time from the initial contact with the force plates to maximum knee flexion [36-39]. The average of the maximum knee flexion and valgus angles in both knees of the five trials of each landing technique were calculated for analysis. Similarly, EMG root mean square data were collected during this period of time with EMGWorks ${ }^{\circledR}$ (Delsys, Inc., Boston, MA, USA) at a sampling rate of $2000 \mathrm{~Hz}$ and filtered through a Butterworth $2^{\text {nd }}$-order bandpass filter (cut-off frequency: $100-400 \mathrm{~Hz}, 160 \mathrm{~dB} / \mathrm{Dec}$.). A dynamic normalization procedure was utilized to determine the percentage of muscle activation during the landing phase [35, 37-39].

Peak ground reaction forces derived from the F-Scan were normalized per each subject's body weight. In order to evaluate jumping performance, the reactive strength index was estimated by dividing the height of the marker placed at the second sacral verte-

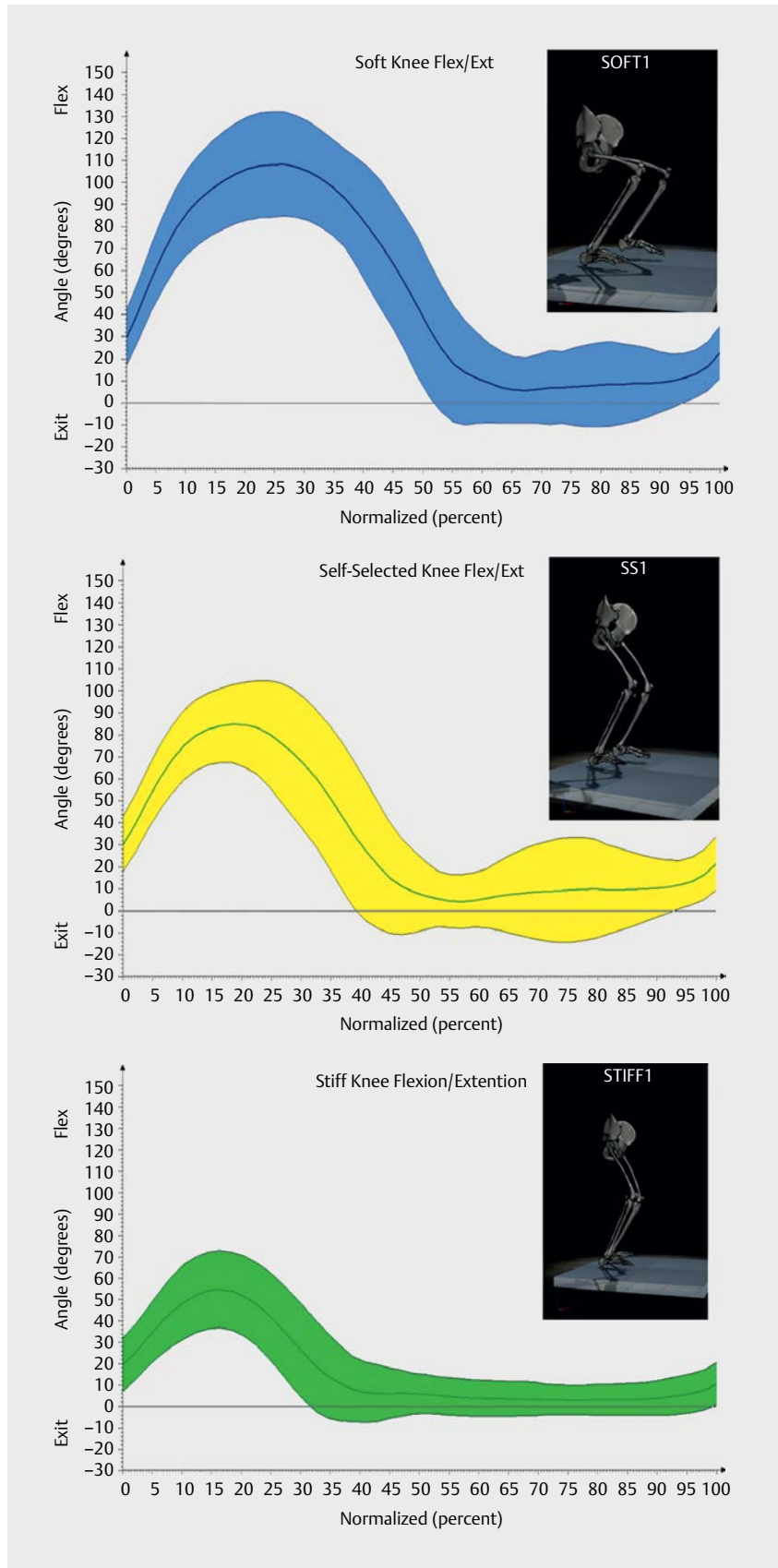

- Fig. 1 Representation of normalized landing phase for all three jumps. Initial contact with the force plates is represented as zero with $100 \%$ representing take-off towards the countermovement jump. The solid line represents mean values while shaded area represents the $95 \%$ confidence interval.

brae by the total contact time with the floor derived from the F-Scan sensors (height/contact time). Previous researchers have calculated the reactive strength index (RSI) during dynamic activities as an indicator of the ability to change from an eccentric to concentric muscular contraction showing excellent reliability $($ ICC $>0.90)$ $[13,17,48]$. The trial-to-trial reliability of the RSI for the landing tasks in this investigation was 0.97 for the SF and ST conditions and 0.96 for the SS. 
- Table 1 Means and standard deviations for all variables between the three jumps.

\begin{tabular}{|c|c|c|c|}
\hline Variable & $\begin{array}{c}\text { Soft } \\
\text { Mean } \pm \text { SD } \\
95 \% \mathrm{Cl}\end{array}$ & $\begin{array}{c}\text { Stiff } \\
\text { Mean } \pm \text { SD } \\
95 \% \mathrm{Cl}\end{array}$ & $\begin{array}{c}\text { Self-selected } \\
\text { Mean } \pm \text { SD } \\
95 \% \mathrm{Cl}\end{array}$ \\
\hline Knee flexion $\left({ }^{\circ}\right)^{a}$ & $\begin{array}{l}116.1 \pm 11.1^{b} \\
111.7-120.5\end{array}$ & $\begin{array}{c}60.4 \pm 13.1^{b} \\
55.2-65.6\end{array}$ & $\begin{array}{c}89.5 \pm 14.6^{b} \\
83.7-95.2\end{array}$ \\
\hline Knee valgus $\left({ }^{\circ}\right)$ & $\begin{array}{l}6.6 \pm 7.4 \\
3.6-9.5\end{array}$ & $\begin{array}{l}5.6 \pm 5.7 \\
3.4-7.8\end{array}$ & $\begin{array}{l}7.3 \pm 7.7 \\
4.2-10.3\end{array}$ \\
\hline $\begin{array}{l}\text { Peak pressure } \\
(\% \mathrm{BW})^{\mathrm{a}}\end{array}$ & $\begin{array}{c}1.3 \pm 1.3^{b} \\
1.2-1.4 \\
\end{array}$ & $\begin{array}{c}1.8 \pm 0.7^{b} \\
1.5-2.0 \\
\end{array}$ & $\begin{array}{c}1.5 \pm 0.3^{b} \\
1.3-1.6 \\
\end{array}$ \\
\hline $\mathrm{RSI}^{\mathrm{a}}$ & $\begin{array}{c}0.6 \pm 0.3^{b} \\
0.5-0.7\end{array}$ & $\begin{array}{c}0.9 \pm 0.5 \\
0.7-1.1\end{array}$ & $\begin{array}{c}0.9 \pm 0.4 \\
0.8-1.1\end{array}$ \\
\hline \multicolumn{4}{|c|}{$\begin{array}{l}\text { a Statistically significant differences between all jumps from RepANOVA; } \\
\text { b Statistically significant differences between jumps after post-hoc } \\
\text { analysis; } 95 \% \text { Cl: } 95 \% \text { confidence interval; SD: standard deviation }\end{array}$} \\
\hline
\end{tabular}

- Table 2 Root mean square (RMS) electromyography variables between the three jumps.

\begin{tabular}{|c|c|c|c|}
\hline Muscle & $\begin{array}{c}\text { Soft Mean } \pm \text { SD } \\
(\mu \mathrm{V}) \\
95 \% \mathrm{Cl}\end{array}$ & $\begin{array}{c}\text { StiffMean } \pm \text { SD } \\
(\mu \mathrm{V}) \\
95 \% \mathrm{Cl}\end{array}$ & $\begin{array}{c}\text { Self-selected- } \\
\text { Mean } \pm \text { SD }(\mu \mathrm{V}) \\
95 \% \mathrm{Cl}\end{array}$ \\
\hline $\begin{array}{l}\text { Gluteus } \\
\text { maximus }\end{array}$ & $\begin{array}{l}43.6 \pm 14.5 \\
38.1-49.1\end{array}$ & $\begin{array}{l}44.2 \pm 12.6 \\
39.4-48.9\end{array}$ & $\begin{array}{c}40.7 \pm 14.5 \\
35.3-46.4\end{array}$ \\
\hline Quadriceps & $\begin{array}{l}33.6 \pm 17.3 \\
27.0-40.2\end{array}$ & $\begin{array}{l}30.8 \pm 16.9 \\
24.4-37.3\end{array}$ & $\begin{array}{l}28.6 \pm 15.8 \\
22.6-34.6\end{array}$ \\
\hline Hamstrings & $\begin{array}{c}42.7 \pm 15.3 \\
36.8-48.5\end{array}$ & $\begin{array}{l}43.9 \pm 16.7 \\
37.6-50.3\end{array}$ & $\begin{array}{l}39.5 \pm 15.1 \\
33.8-45.3\end{array}$ \\
\hline $\begin{array}{l}\text { Tibialis } \\
\text { anterior }\end{array}$ & $\begin{array}{c}40.5 \pm 19.5 \\
33.2-48.0\end{array}$ & $\begin{array}{c}43.3 \pm 16.1 \\
37.2-49.4\end{array}$ & $\begin{array}{c}39.2 \pm 16.6 \\
32.9-45.5\end{array}$ \\
\hline $\begin{array}{l}\text { Gastroc- } \\
\text { nemius }\end{array}$ & $\begin{array}{l}32.7 \pm 10.1 \\
28.8-36.5\end{array}$ & $\begin{array}{l}31.8 \pm 14.5 \\
26.3-37.3\end{array}$ & $\begin{array}{l}31.7 \pm 11.6 \\
27.3-36.1\end{array}$ \\
\hline
\end{tabular}

\section{Data analysis}

The Shapiro-Wilk test, Levene's test, and box plots were utilized to screen knee flexion and valgus angles, RSI, EMG, and peak pressure data for normality assumptions, homoscedasticity, and outliers, respectively. A paired t-test was performed to evaluate differences between legs for knee flexion and valgus angles and peak pressure to determine any differences between legs. Individual betweencondition (landing task) repeated measures one-way analyses of variance (RepANOVA) were performed to compare knee flexion, knee valgus, peak pressure, EMG, and RSI between the three landing techniques. Post-hoc Bonferroni analyses were performed if RepANOVA was statistically significant. Alpha level was set at 0.05 for statistical significance. Statistical analyses were performed using SPSS ${ }^{\circledR} 19.0$ (SPSS Inc., Chicago, IL, USA).

\section{Results}

Knee flexion and valgus angles, RSI, EMG, and peak pressure data met the assumptions of normality, homoscedasticity, and outliers. The paired t-test showed no statistical differences $(p>0.13)$ between legs for knee flexion and valgus angles across all three conditions. Therefore, the average of both legs for all variables was used for each participant. The RepANOVAs showed significant differences among the three landing techniques only for knee flexion angles $\left(F(2,25)=127.03 ; \rho<0.001 ; \eta^{2}: 0.91 ; \beta: 0.99\right), \operatorname{RSI}(F(2$, $\left.24)=27.22 ; \rho<0.001 ; \eta^{2}: 0.70 ; \beta: 0.99\right)$, and peak pressure $(F(2$, $\left.28)=10.72 ; \rho<0.001 ; \eta^{2}: 0.43 ; \beta: 0.98\right)$. No statistical differences were found among the three landing techniques for the knee valgus angles $\left(F(2,25)=2.26 ; \rho=0.12 ; \eta^{2}: 0.15 ; \beta: 0.42\right)$. Post-hoc analyses for knee flexion joint angles showed that SF $\left(116^{\circ}\right)$ was higher than SS [ $\left(89^{\circ}\right) ; \mathrm{p}<0.001 ; \eta^{2}: 0.72 ; 95 \% \mathrm{Cl}: 19.34-33.96 ; \beta$ : $0.91]$ and ST [ $\left(60^{\circ}\right) ; p<0.001 ; \eta^{2}: 0.92 ; 95 \% \mathrm{Cl}: 46.62-64.81 ; \beta$ : $0.91]$ ( $\triangleright$ Table 1). Similarly, SS $\left(89^{\circ}\right)$ was higher than ST [ $\left(60^{\circ}\right)$; $\left.\mathrm{p}<0.001 ; \eta^{2}: 0.72 ; 95 \% \mathrm{Cl}: 19.50-38.63 ; \beta: 0.91\right]$. Compared to SS (1.50/bw) and SF (1.34/bw), ST (1.81/bw) peak pressure was higher $\left(p<0.001 ; \eta^{2}: 0.41 ; 95 \% \mathrm{Cl}:-.72-.21\right.$ and $p=.01 ; \eta^{2}: 0.29 ; 95 \%$ Cl:.07-.55; $\beta: 0.98$, respectively). Likewise, SS (1.50.bw) peak pressure was significantly greater $\left(p=0.01 ; \eta^{2}: 0.23 ; 95 \% \mathrm{Cl}: 0.03-0.28\right.$; $\beta: 0.98)$. The RSI was statistically significant $\left(p<0.001 ; \eta^{2}: 0.69 ; \beta\right.$ : 0.99 ) with the SS (0.96) showing the highest value, followed by ST (0.93), and SF (0.64). However, the RSI did not show significant differences between ST and SS landings ( $\triangleright$ Table 1$)$. No differences were observed among the three landing styles for all EMG variables $\left(F(5,24)=0.77 ; \rho>0.66 ; \eta^{2}: 0.29 ; \beta: 0.27\right)(\triangleright$ Table 2$)$.

\section{Discussion}

The purpose of this investigation was to determine which of the three landing techniques - SF, SS, or ST - demonstrated safer landing mechanics, greater jumping performance, and better neuromuscular activation of lower extremity muscles. The results of this investigation partially supported our hypothesis that both ST and SS landing styles would demonstrate safe landing mechanics with greater jumping performance than the SF landing. In this investigation, we analyzed landing mechanics by looking at the knee flexion and knee valgus angles, which are major contributors to $\mathrm{ACL}$ loading during landing $[15,18,22,31]$. Several investigators have reported that increased knee valgus angles during landing are associated with increased ACL loading $[15,18,22,31]$. Consequently, landing techniques that are characterized by smaller knee valgus angles may decrease the risk of ACL injury. In our investigation, there were no significant differences in the knee valgus angles among all three landing techniques, indicating all of them can be performed safely without increasing the predisposition to ACL injury. This finding agrees with a previous investigation in which knee valgus was not significantly different between soft and stiff landings in healthy individuals [34]. Myers et al. [34] reported no differences in tibial anterior translation, knee internal and external rotation, and knee valgus/varus during soft and stiff landings via fluoroscopy in healthy adults during a 40-cm drop landing.

On the other hand, it has been previously reported that decreased knee flexion angle during landing increases the risk of $\mathrm{ACL}$ injuries [15, 18, 22, 31]. Dai et al. [7] have demonstrated that soft landings may decrease the ACL loading during dynamic tasks. In the current study, the knee flexion angle was significantly different among all three landing styles, indicating each landing style was in fact different from each other. As expected, the SF landing style showed the highest knee flexion angles $\left(116^{\circ}\right)$, whereas the ST landing $\left(60^{\circ}\right)$ style showed the lowest knee flexion angles. Further- 
more, another important factor in determining safe landing mechanics are ground reaction forces (GRFs) [7, 49]. It has been reported that high GRFs during landing have been associated with greater ACL loading [49], suggesting athletes may need to decrease their GRFs during landing in an attempt to minimize ACL loading. In the current investigation, the peak pressure was significantly different among all three landing styles. Participants had the highest peak pressure values during the ST landing style (1.8/bw), whereas the lowest peak pressure values were observed during the SF landing style $(1.34 / \mathrm{bw})$. This finding is supported by previous investigations in which participants exhibiting greater knee flexion also were able to decrease peak GRF during a soft landing when compared with a stiff landing, allowing greater dissipation of GRFs $[7,34]$.

In regard to jumping performance, the results supported the hypothesis that the stiff and self-selected landing techniques would demonstrate greater jumping performance as measured by RSI. Previous investigators have examined jumping performance by evaluating stance phase [47], jump height [47], and mechanical work [10,50] during soft landings. Dai et al. [7] examined jumping performance by evaluating stance time, lower extremity mechanical work, jump height and movement speed during stop-jump and side-cutting under soft landing and preferred landing conditions [7]. The researchers reported that the soft landing demonstrated decreased jump height and movement speed and increased stance time and mechanical work compared with the natural landing. Furthermore, other investigators have reported that the soft landing increased stance time and lower extremity mechanical work during a drop vertical jump and drop landing tasks, respectively $[10,47,50]$. These studies agree with our findings that the soft landing style significantly decreased jumping performance compared with the stiff and self-selected landing styles, with the soft landing exhibiting the lowest RSI, whereas self-selected landing styles had the highest RSI during drop landing tasks. The decreased RSI observed during soft landing style is theorized to be due to greater ground contact time given that soft landings allow greater hip and knee flexion range of motion during landing [10, 50].

Lower extremity muscle groups play a major role in energy absorption during landing maneuvers [10,26, 50]. Previous investigators have reported that soft landings demonstrated greater energy absorption through the hip and knee extensors, whereas ankle plantar flexion absorbed more energy during stiff landings $[9,10,50]$. However, the results of this investigation do not agree with these investigations in which neuromuscular performance was significantly different between soft and stiff landings. In our investigation, there was no significant difference in the neuromuscular performance among all three landing styles, indicating lower extremity muscular control can compensate for the differences in landing without increasing the predisposition to injury [34].

The current investigation had several limitations that need to be considered. First, participants recruited in this investigation were at the recreational level, making the generalizability of this study to those participating in highly competitive sports settings limited. Second, the drop landing task chosen in this investigation did not simulate real competitive games in which unanticipated landings that predispose athletes to lower extremity injury usually occur. Another limitation is that although participants were asked to land with 60 degrees of knee flexion during soft landings, most landed with more than 90 degrees as measured by the motion analysis system. Stiff landings were actually closer to 60 degrees as measured by the motion analysis system even though they appeared to be less than 30 degrees to the naked eye.

In summary, the current study showed that stiff and self-selected landing styles can be performed without increasing peak knee valgus angles while increasing jumping performance compared with soft landing styles. Additionally, all three landing styles exhibited safe landing mechanics in terms of knee valgus. Therefore, a self-selected landing style will safely minimize risk of ACL injury without inhibiting jumping performance. Athletes that demonstrate unsafe knee valgus should be trained at their self-selected jump depth to improve strength and motor control to decrease this risk factor while maintaining jumping performance.

\section{Conflict of Interest}

The authors declare that they have no conflict of interest

\section{References}

[1] Ahroni JH, Boyko EJ, Forsberg R. Reliability of F-Scan in-shoe measurements of plantar pressure. Foot Ankle Int 1998; 19: 668-673

[2] Alanazi A. Biomechanical evaluation of landing maneuvers in soccer players with anterior cruciate ligament reconstruction [Dissertation]. Denton, TX: Texas Woman's University; 2017

[3] Boden BP, Dean GS, Feagin JA Jr, Garrett WE Jr. Mechanisms of anterior cruciate ligament injury. Orthopedics 2000; 23: 573-578

[4] Chen B, Bates BT. Comparison of F-Scan in-sole and AMTI forceplate system in measuring vertical ground reaction force during gait. Physiother Theory Pract 2009; 16: 43-53

[5] Criswell E, Cram JR. Cram's Introduction to Surface Electromyography. 2nd ed. Sudbury, MA: Jones and Bartlett; 2011

[6] Dai B, Garrett WE, Gross MT, Padua D, Queen RM, Yu B. The effect of performance demands on lower extremity biomechanics during landing and cutting tasks. J Sport Health Sci 2016, doi:10.1016/j. jshs.2016.11.004

[7] Dai B, Garrett WE, Gross MT, Padua DA, Queen RM, Yu B. The effects of 2 landing techniques on knee kinematics, kinetics, and performance during stop-jump and side-cutting tasks. Am J Sports Med 2015; 43: 466-474

[8] Dai B, Herman D, Liu H, Garrett WE, Yu B. Prevention of ACL injury, part 1: Injury characteristics, risk factors, and loading mechanism. Res Sports Med 2012; 20: 180-197

[9] Decker M], Torry MR, Wyland DJ, Sterett WI, Richard Steadman J. Gender differences in lower extremity kinematics, kinetics and energy absorption during landing. Clin Biomech (Bristol, Avon) 2003; 18: 662-669

[10] Devita P, Skelly WA. Effect of landing stiffness on joint kinetics and energetics in the lower extremity. Med Sci Sports Exerc 1992; 24 : 108-115

[11] Donnell-Fink LA, Klara K, Collins JE, Yang HY, Goczalk MG, Katz JN, Losina E. Effectiveness of knee injury and anterior cruciate ligament tear prevention programs: a meta-analysis. PLoS One 2015; 10 : e0144063

[12] Dowling AV, Favre J, Andriacchi TP. Inertial sensor-based feedback can reduce key risk metrics for anterior cruciate ligament injury during jump landings. Am J Sports Med 2012; 40: 1075-1083 
[13] Ebben WP, Petushek E]. Using the reactive strength index modified to evaluate plyometric performance. J Strength Cond Res 2010; 24: 1983-1987

[14] Emery CA, Roy TO, Whittaker JL, Nettel-Aguirre A, van Mechelen W. Neuromuscular training injury prevention strategies in youth sport: $A$ systematic review and meta-analysis. Br J Sports Med 2015; 49: 865-870

[15] Fagenbaum R, Darling WG. Jump landing strategies in male and female college athletes and the implications of such strategies for anterior cruciate ligament injury. Am J Sports Med 2003; 31: 233-240

[16] Fauno P, Wulff Jakobsen B. Mechanism of anterior cruciate ligament injuries in soccer. Int J Sports Med 2006; 27: 75-79

[17] Flanagan EP, Ebben WP, Jensen RL. Reliability of the reactive strength index and time to stabilization during depth jumps. J Strength Cond Res 2008; 22: 1677-1682

[18] Ford KR, Myer GD, Toms HE, Hewett TE. Gender differences in the kinematics of unanticipated cutting in young athletes. Med Sci Sports Exerc 2005; 37: 124-129

[19] Griffin LY, Agel J, Albohm M], Arendt EA, Dick RW, Garrett WE, Garrick JG, Hewett TE, Huston L, Ireland ML, Johnson RJ, Kibler WB, Lephart S, Lewis JL, Lindenfeld TN, Mandelbaum BR, Marchak P, Teitz CC, Wojtys EM. Noncontact anterior cruciate ligament injuries: Risk factors and prevention strategies. J Am Acad Orthop Surg 2000; 8: 141-150

[20] Griffin LY, Albohm M], Arendt EA, Bahr R, Beynnon BD, Demaio M, Dick RW, Engebretsen L, Garrett WE Jr, Hannafin JA, Hewett TE, Huston LJ, Ireland ML, Johnson RJ, Lephart S, Mandelbaum BR, Mann BJ, Marks PH, Marshall SW, Myklebust G, Noyes FR, Powers C, Shields C Jr, Shultz SJ, Silvers H, Slauterbeck J, Taylor DC, Teitz CC, Wojtys EM, Yu B. Understanding and preventing noncontact anterior cruciate ligament injuries: A review of the hunt valley II meeting, January 2005. Am J Sports Med 2006; 34: 1512-1532

[21] Harriss D], Atkinson G. Ethical standards in sport and exercise science research: 2016 update. Int J Sports Med 2015; 36: 1121-1124

[22] Hewett TE, Myer GD, Ford KR, Heidt RS Jr, Colosimo AJ, McLean SG, van den Bogert AJ, Paterno MV, Succop P. Biomechanical measures of neuromuscular control and valgus loading of the knee predict anterior cruciate ligament injury risk in female athletes: A prospective study. Am J Sports Med 2005; 33: 492-501

[23] Jordan SS, DeFrate LE, Nha KW, Papannagari R, Gill TJ, Li G. The in vivo kinematics of the anteromedial and posterolateral bundles of the anterior cruciate ligament during weightbearing knee flexion. Am J Sports Med 2007; 35: 547-554

[24] Kadaba MP, Ramakrishnan HK, Wootten ME. Measurement of lower extremity kinematics during level walking. J Orthop Res 1990; 8: 383-392

[25] Kirkendall DT, Garrett WE Jr. The anterior cruciate ligament enigma. Injury mechanisms and prevention. Clin Orthop Relat Res 2000; 64-68

[26] Kulas AS, Schmitz RJ, Schultz SJ, Watson MA, Perrin DH. Energy absorption as a predictor of leg impedance in highly trained females. J Appl Biomech 2006; 22: 177-185

[27] Laughlin WA, Weinhandl JT, Kernozek TW, Cobb SC, Keenan KG, O'Connor KM. The effects of single-leg landing technique on ACL loading. J Biomech 2011; 44: 1845-1851

[28] Markolf KL, Burchfield DM, Shapiro MM, Shepard MF, Finerman GA, Slauterbeck JL. Combined knee loading states that generate high anterior cruciate ligament forces. J Orthop Res 1995; 13: 930-935

[29] McKay CD, Merrett CK, Emery CA. Predictors of FIFA 11 + implementation intention in female adolescent soccer: An application of the Health Action Process Approach (HAPA) model. Int J Environ Res Public Health 2016; 13:

[30] McKay CD, Steffen K, Romiti M, Finch CF, Emery CA. The effect of coach and player injury knowledge, attitudes and beliefs on adherence to the FIFA 11 + programme in female youth soccer. $\mathrm{Br}$ J Sports Med 2014; 48: 1281-1286
[31] McLean SG, Huang X, Su A, Van Den Bogert AJ. Sagittal plane biomechanics cannot injure the ACL during sidestep cutting. Clin Biomech (Bristol, Avon) 2004; 19: 828-838

[32] Moran KA, Wallace ES. Eccentric loading and range of knee joint motion effects on performance enhancement in vertical jumping. Hum Mov Sci 2007; 26: 824-840

[33] Myers CA, Hawkins D. Alterations to movement mechanics can greatly reduce anterior cruciate ligament loading without reducing performance. J Biomech 2010; 43: 2657-2664

[34] Myers CA, Torry MR, Peterson DS, Shelburne KB, Giphart JE, Krong JP, Woo SL, Steadman JR. Measurements of tibiofemoral kinematics during soft and stiff drop landings using biplane fluoroscopy. Am J Sports Med 2011; 39: 1714-1722

[35] Ortiz A, Capo-Lugo CE, Venegas-Rios HL. Biomechanical deficiencies in women with semitendinosus-gracilis anterior cruciate ligament reconstruction during drop jumps. PM R 2014; 6: 1097-1106

[36] Ortiz A, Olson S, Libby CL, Kwon YH, Trudelle-Jackson E. Kinematic and kinetic reliability of two jumping and landing physical performance tasks in young adult women. N Am J Sports Phys Ther 2007; 2: 104-112

[37] Ortiz A, Olson S, Libby CL, Trudelle-Jackson E, Kwon YH, Etnyre B, Bartlett W. Landing mechanics between noninjured women and women with anterior cruciate ligament reconstruction during 2 jump tasks. Am J Sports Med 2008; 36: 149-157

[38] Ortiz A, Olson S, Trudelle-Jackson E, Rosario M, Venegas HL. Landing mechanics during side hopping and crossover hopping maneuvers in noninjured women and women with anterior cruciate ligament reconstruction. PM R 2011; 3: 13-20

[39] Ortiz A, Olson SL, Etnyre B, Trudelle-Jackson EE, Bartlett W, VenegasRios HL. Fatigue effects on knee joint stability during two jump tasks in women. J Strength Cond Res 2010; 24: 1019-1027

[40] Randolph AL, Nelson M, Akkapeddi S, Levin A, Alexandrescu R. Reliability of measurements of pressures applied on the foot during walking by a computerized insole sensor system. Arch Phys Med Rehabil 2000; 81: 573-578

[41] Sakane M, Fox RJ, Woo SL, Livesay GA, Li G, Fu FH. In situ forces in the anterior cruciate ligament and its bundles in response to anterior tibial loads. J Orthop Res 1997; 15: 285-293

[42] Steffen K, Bakka HM, Myklebust G, Bahr R. Performance aspects of an injury prevention program: $A$ ten-week intervention in adolescent female football players. Scand J Med Sci Sports 2008; 18: 596-604

[43] Taylor KA, Terry ME, Utturkar GM, Spritzer CE, Queen RM, Irribarra LA, Garrett WE, DeFrate LE. Measurement of in vivo anterior cruciate ligament strain during dynamic jump landing. J Biomech 2011; 44: 365-371

[44] Vescovi JD, VanHeest JL. Effects of an anterior cruciate ligament injury prevention program on performance in adolescent female soccer players. Scand J Med Sci Sports 2010; 20: 394-402

[45] Vicon Motion Systems. Plug-in Gait: Product guide foundational notes. Denver: Vicon Motion Systems; 2010

[46] Vidmar G, Novak P. Reliability of in-shoe plantar pressure measurements in rheumatoid arthritis patients. Int J Rehabil Res 2009; 32: 36-40

[47] Walsh MS, Waters J, Kersting UG. Gender bias on the effects of instruction on kinematic and kinetic jump parameters of high-level athletes. Res Sports Med 2007; 15: 283-295

[48] Young W. Laboratory strength assessment of athletes. New Stud Athlet 1995; 10: 89-89

[49] Yu B, Garrett WE. Mechanisms of non-contact ACL injuries. Br J Sports Med 2007; 41: (Suppl 1): 47-51

[50] Zhang SN, Bates BT, Dufek JS. Contributions of lower extremity joints to energy dissipation during landings. Med Sci Sports Exerc 2000; 32: 812-819 